\title{
Genes regulated by the Escherichia coli SOS repressor LexA exhibit heterogenous expression
}

\author{
Simona Kamenšek1', Zdravko Podlesek', Osnat Gillor², Darja Žgur-Bertok ${ }^{1 *}$
}

\begin{abstract}
Background: Phenotypic heterogeneity may ensure that a small fraction of a population survives environmental perturbations or may result in lysis in a subpopulation, to increase the survival of siblings. Genes involved in DNA repair and population dynamics play key roles in rapid responses to environmental conditions. In Escherichia coli the transcriptional repressor LexA controls a coordinated cellular response to DNA damage designated the SOS response. Expression of LexA regulated genes, e.g. colicin encoding genes, recA, lexA and umuDC, was examined utilizing transcription fusions with the promoterless $g f p$ at the single cell level.

Results: The investigated LexA regulated genes exhibited heterogeneity, as only in a small fraction of the population more intense fluorescence was observed. Unlike recA and lexA, the pore forming and nuclease colicin activity genes as well as umuDC, exhibited no basal level activity. However, in a lexA defective strain high level expression of the gene fusions was observed in the large majority of the cells. All of the investigated genes were expressed in a recA defective strain, albeit at lower levels, revealing expression in the absence of a spontaneous SOS response. In addition, the simultaneous expression of $c k a$, encoding the pore forming colicin $\mathrm{K}$, and lexA, investigated at the single cell level revealed high level expression of only cka in rare individual cells.

Conclusion: LexA regulated genes exhibit phenotypic heterogeneity as high level expression is observed in only a small subpopulation of cells. Heterogenous expression is established primarily by stochastic factors and the binding affinity of LexA to SOS boxes.
\end{abstract}

\section{Background}

Genetically identical bacterial cells can exhibit heterogeneity as the population bifurcates into distinct subpopulations. Such heterogeneity within clonal populations is a bet hedging strategy as a small fraction of a population is either prepared to survive adverse environmental conditions or sacrifice itself to enhance the likelihood of survival of clonal siblings. Examples of phenotypic heterogeneity include: development of competence and sporulation in Bacillus subtilis, lysogenic versus the lytic cycle of bacteriophage lambda, biofilm formation, toxin production and antibiotic persistence [1-4].

In Escherichia coli DNA damage induces the expression of more than 40 genes leading to arrest of cell division and the induction of DNA repair, prophages, toxin production and mutagenesis [5]. The key regulator of

\footnotetext{
* Correspondence: darja.zgur.bertok@bf.uni-lj.si

'Dept. of Biology, Biotechnical Faculty, University of Ljubljana, Večna pot 111, Slovenia

Full list of author information is available at the end of the article
}

this coordinated cellular response, named the SOS response [6], is the LexA protein that represses gene expression by binding as a dimer to a 16-mer consensus sequence CTG- $\mathrm{N}_{10}$-CAG designated as SOS boxes [7]. Upon DNA damage replication forks are stalled exposing single-stranded DNA (ssDNA). RecA binds to the ssDNA forming a nucleoprotein filament which activates the autoproteolytic cleavage of LexA, leading to induction of the SOS response. In addition to activation by exogenous DNA damaging agents, the SOS response is also induced by endogenous, as well as spontaneous events [5].

SOS induction often results in the production of antimicrobial toxins such as bacteriocins. The bacteriocins of $E$. coli strains, designated as colicins, are plasmid encoded and are found with high frequency among natural isolates [8]. These toxins were suggested to promote phenotypic and genotypic diversity within E. coli populations in the mammalian colon $[9,10]$. Colicins destroy cells by one of three mechanisms: (i) they either
Ciomed Central

C 2010 Kamenšek et al; licensee BioMed Central Ltd. This is an Open Access article distributed under the terms of the Creative Commons Attribution License (http://creativecommons.org/licenses/by/2.0), which permits unrestricted use, distribution, and reproduction in any medium, provided the original work is properly cited. 
form pores in the cytoplasmic membrane thus depleting its electrochemical potential, (ii) degrade either the DNA or RNA of their target cell or (iii) inhibit peptidoglycan and lipopolysaccharide (LPS) O-antigen biosynthesis [11-13]. Production and release of most colicins is encoded by three genes, an activity gene encoding the colicin protein, an immunity gene encoding a protein that protects the cell from its produced toxin and a lysis gene for semispecific release of the colicin. Colicin encoding genes characteristically have two overlapping SOS boxes that bind two LexA dimers and protect the cell from untimely colicin production, as it is lethal to the producing cell [14]. Some colicins, such as colicins $B$ and $M$, have no lysis genes and are actively secreted by an unknown mechanism [15]. Colicin B and $M$ encoding operons are tightly linked on large conjugative plasmids [16,17]. Expression of both colicin B and colicin $\mathrm{M}$ seems to be regulated by a common SOS boxes located upstream of the colicin B activity gene $[16,18]$.

In previous studies we showed that the pore forming colicin $\mathrm{K}$ activity gene $c k a$ is expressed in only a small fraction of a bacterial population while the immunity gene encoding the immunity protein is expressed in the large majority of the cells $[3,19]$. In the present study we investigated, at the single cell level, expression of the activity genes of several other colicins namely, the pore formers A, E1 and N, the DNase colicin E7 and the LPS synthesis inhibitor, colicin M. We compared the single cell colicin expression to the expression of other LexA regulated genes, e.g. $\operatorname{rec} A$, $\operatorname{lex} A$ and $u m u D C$, and finally we examined the simultaneous expression of the colicin encoding $c k a$ gene and the lexA gene.

\section{Methods}

\section{Bacterial strains, plasmids and growth conditions}

The bacterial strains and plasmids used in this study are presented in Table 1. Bacteria were grown in LuriaBertani (LB) with aeration at $37^{\circ} \mathrm{C}$ and with the appropriate antibiotics. Ampicillin and kanamycin (Sigma, St Louis MO, USA) were used at concentrations $100 \mu \mathrm{g} \mathrm{ml}^{-1}$ and $30 \mu \mathrm{g} \mathrm{l^{-1 }}$, respectively.

\section{General DNA techniques}

Plasmid DNA isolation was performed with the Gene$\mathrm{JET}^{\mathrm{T}}$ plasmid miniprep kit (Fermentas, Burlington, Canada). Standard procedures were used for gel electrophoresis, ligations and transformation experiments [20]. Restriction endonuclease digestion was performed according to the instructions of the manufacturer (Fermentas). The PCR amplified fragments were purified using the QIAquick PCR purification kit (Qiagen, Hamburg, Germany). DNA fragments were isolated from agarose gels by using a QIAquick gel extraction kit (Qiagen).

\section{Construction of promoter fusions}

PCR was carried out to amplify the promoter regions with an additional $73-93$ bp of the flanking colicin encoding gene for colicins A (486 bp), E1 (508 bp), E7 (501 bp), N (499 bp) and M (298 bp) with the primers listed in Table 2. All primers have added BamHI and XhoI restriction sites. The PCR generated fragments were cut with BamHI and XhoI (Fermentas), and ligated into the low copy number pSC101 [21] based plasmid with a promoterless (GFPmut3) $g f p$ also cut with the same two enzymes.

The promoterless DsRed-Express2 gene, which is part of a gene cassette on plasmid pDsRed-Express2-N1, was cloned into the natural colicin $\mathrm{K}$ encoding plasmid pColK-K235 manipulated to carry the Ap ${ }^{\mathrm{r}}$ gene as a selectable marker, and a KpnI restriction site in the $c k a$ gene. A cassette carrying the promoterless $g f p$ was inserted at the KpnI restriction site [19]. The ckaDsRed-Express2 transcriptional fusion was constructed by replacing the $K p n \mathrm{I}$ fragment harboring the promoterless $g f p$ with the in frame promoterless DsRed-Express2 [22] amplified by PCR (Table 2) which was prior to ligation also cut with KpnI. Only cells with an active $c k a$ promoter can express DsRed-Express2.

Nucleotide sequencing was performed to confirm that no base changes had occurred during amplification. The sequences have been deposited in the GenBank Nucleotide sequence database under accession numbers, HM449002 (caa promoter region), HM449003 (cna promoter region), HM449004 (ce1a promoter region), HM449005 (ce7a promoter region), HM449006 (cma promoter region).

\section{Fluorescence microscopy}

Strains RW118 and RW464 carrying different colicin promoter region- $g f p$ transcriptional fusions, and control strains without plasmid carrying $g f p$ fusions, were grown with aeration at $37^{\circ} \mathrm{C}$. Samples were removed at early stationary phase and chloramphenicol $\left(500 \mu \mathrm{g} \mathrm{ml}^{-1}\right)$ (Sigma) was added to block protein synthesis. Prior to microscopy, cells were attached to glass slides coated with $0.1 \%$ (wt vol ${ }^{-1}$ ) poly-L-lysine (Sigma). Fluorescence microscopy to detect expression in single cells was performed using an inverted microscope (Nikon Eclipse TE300), equipped with a Nikon digital camera DXM 1200, and a $488 \mathrm{~nm}$ Argon-Ion laser as well as bright field microscopy.

The examined cells were counted with software for quantification of bacteria by automated image analysis cellC http://www.cs.tut.fi/sgn/csb/cellc/. The fluorescence intensity of individual cells was estimated using image analysis software Scion Image http://www.scioncorp.com as previously described [3]. The fluorescent micrographs were converted to greyscale images. The 
Table $1 \mathrm{E}$. coli strains and plasmids used in the presented study

\begin{tabular}{|c|c|c|}
\hline Bacterial strains & Relevant properties & Source/reference \\
\hline RW118 & thr-1 araD139 $\Delta(g p t-p r o A) 62$ lacY1 tsx-33 supE44 galK2 hisG4 rpsL31 xyl-5 mtl-1 argE thi-1 sulA211 & R. Woodgate \\
\hline RW464 & RW118 recA & R. Woodgate \\
\hline RW542 & RW118 lexA51 (Def) & R. Woodgate \\
\hline \multicolumn{3}{|l|}{ Plasmids } \\
\hline pSC101 derivative & pSC101 low copy plasmid origin with promoterless GFPmut3 gene, $\mathrm{Kn}^{r}$ & 21 \\
\hline pSC300 & caa-gfp Kn $\mathrm{K}^{\mathrm{r}}$ & This study \\
\hline pSC301 & cna-gfp Kn ${ }^{r}$ & This study \\
\hline pSC302 & cela-gfp $\mathrm{Kn}^{r}$ & This study \\
\hline pSC303 & ce7a-gfp $\mathrm{Kn}^{\mathrm{r}}$ & This study \\
\hline pSC304 & cma-gfp $\mathrm{Kn}^{r}$ & This study \\
\hline$\overline{p C o l A-C A 31}$ & caa cai cal & A. P. Pugsley \\
\hline pColN-284 & cna cni cnl & A. P. Pugsley \\
\hline pColE1-K53 & cela celicell & A. P. Pugsley \\
\hline pColE7-K317 & ce7a ce7i ce7l & A. P. Pugsley \\
\hline pCHAP1 & $\mathrm{cma}$ & A. P. Pugsley \\
\hline pSC200 & lexA-gfp $\mathrm{Kn}^{r}$ & 21 \\
\hline pSC201 & recA-gfp $\mathrm{Kn}^{r}$ & 21 \\
\hline psC202 & umuD-gfp $\mathrm{Kn}^{\mathrm{r}}$ & 21 \\
\hline pSC203 & uvrA-gfp $\mathrm{Kn}^{r}$ & 21 \\
\hline pDsRed-Express2-N1 & DsRed-Express2 reporter $\mathrm{Kn}^{\mathrm{r}}$ & B. Glick \\
\hline pKCT3 & $c k a-g f p \mathrm{Ap}^{r} \mathrm{Kn}^{r}$ & 19 \\
\hline pKCT10 & cka-DsRed-Express2 Apr & This study \\
\hline
\end{tabular}

density window was established by using density slice matching the shape of the cells with the highest fluorescence intensity and that of the cells with the lowest intensity, gaining the top and the bottom boundaries (respectively) of the density window. For greater clearness the density index scale is determined from 0 (black) to 256 (white). All micrographs were taken at exactly the same conditions; thus the density window gives good correlation to the fluorescence intensity of the analyzed population.

Table 2 Primers used in this study

\begin{tabular}{ll}
\hline Primers & nucleotide sequence $\mathbf{5}^{\prime}$-3' \\
\hline ColA-F & TCCTCGAGATGCTCTGATCAGTTCACT \\
\hline ColA-R & TCGGATCCTACCACCACCCGGCTC \\
\hline ColN-F & TCCTCGAGGATCAGTTCACTGGTTTCA \\
\hline ColN-R & TCGGATCCGCCACTGGTATTACCAATG \\
\hline ColE1-F & TCCTCGAGCAGTTCACTGGTTCAACC \\
\hline ColE1-R & TCGGATCCCCCGTCAGGAGTACCATTC \\
\hline ColE7-F & TCCTCGAGAGGAATACAACACCTTAAA \\
\hline ColE7-R & TCGGATCCTAGGGCCGCCATTAATGTT \\
\hline ColM-F & TCCTCGAGGAGTTCTCAATATATATTTCCAGT \\
\hline ColM-R & TCGGATCCCAGGAACATGCGGTGCTGAA \\
\hline
\end{tabular}

Simultaneous expression of the cka-DsRed-Express 2 and the lexA-gfp fusions was investigated employing a laser scanning Confocal Microscope (Zeiss, Göttingen, Germany).

\section{Results and discussion}

Pore forming and nuclease colicins exhibit heterogeneity

The advent of methods for visualization of gene expression in individual cells has revealed within populations of genetically identical bacteria heterogeneity in expression of certain genes [1-3]. A classical example of heterogeneity is the expression of the $c k a$ gene, encoding the pore forming colicin $\mathrm{K}$; in the absence of exogenous DNA damaging agents $c k a$ is expressed in only a small fraction of the population $[3,19]$ as the producing cells lyse to release the colicin. While colicin expression is characteristically regulated by the LexA protein which binds to overlapping SOS boxes, their regulatory sequences including SOS boxes are not identical. Therefore, we investigated at the single cell level, expression of genes encoding three pore formers (A, E1, N), a DNase colicin (E7) and a LPS inhibitor (colicin M), employing $g f p$ transcriptional fusions. Our results revealed that, as was previously shown for the $c k a$ gene [19], only a small portion of the population expressed the investigated activity genes (colicin A, caa, Figure 1, 


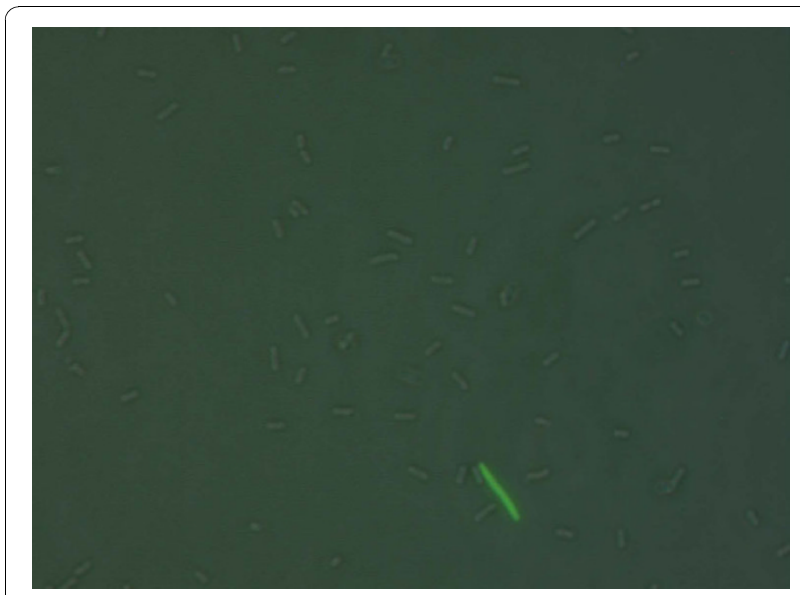

Figure 1 Merged image of the phase contrast and fluorescence images of RW118 with a caa-gfp transcriptional fusion. Only a small subpopulation of cells exhibited high fluorescence intensity, while the large majority of the cells exhibited no fluorescence.

Figure 2 and Table 3). We showed that single cell expression of these genes correlates with the predicted affinity of binding of the LexA protein to the operator sequences (Table 3 ), as expressed by the heterology index (HI). The HI was defined to determine the degree of divergence of any 20 nucleotide sequences from the consensus LexA-binding site [23]. Sequences with a low $\mathrm{HI}$ are closer to the consensus and are predicted to bind LexA with greater affinity than sites with a higher HI. Thus, the colicin E7 SOS boxes, which have the highest $\mathrm{HI}$ values and therefore the lowest predicted affinity of LexA binding, exhibit approximately three fold higher percentage of cells expressing the colicin activity gene compared to the pore forming colicins examined in this study. On the other hand, single cell analysis of cells harboring a $g f p$ fusion with the colicin $\mathrm{M}$ activity gene promoter, $c m a-g f p$, revealed low level expression in the large majority of the investigated cells. Colicin $\mathrm{M}$ was shown to be tightly connected with the upstream colicin $B$ encoding genes and it is presumed that expression of both colicins $\mathrm{B}$ and $\mathrm{M}$ is regulated from common SOS boxes situated upstream of the colicin B activity gene $[16,18]$. Colicins $M$ and $B$ are among the most abundant colicins produced by E. coli strains [24]. We analysed the nucleotide sequences upstream of $\mathrm{cma}$ and found neither colicin regulatory motifs nor any consensus promoter sequence (data not presented). Nonetheless, we detected uniform low-level fluorescence mediated by the colicin M promoter (Figure 2, Table 3).

\section{SOS genes exhibit heterogeneity}

Previously, single cell expression of a sulA-gfp fusion was investigated [25]. SulA is synthesized in large amounts during the SOS response and inhibits cell division by binding to FtsZ, the major component of the cell division machinery [26]. The sulA operator has a HI of 4.65 and thus binds LexA tightly. The authors found that in the absence of exogenous DNA damaging agents only approximately $0.3 \%$ of the examined cells fully expressed sulA.

As RecA is required to initiate the SOS response and LexA to repress the response, both are expressed, albeit at a low level, in the absence of DNA damage. A previous study showed a temporal program of expression of SOS genes upon DNA damage [21]. Subsequently, the response of individual cells to UV irradiation was followed by monitoring the activity of LexA repressed promoters fused to the promoterless $g f p$ [27]. The authors found that the response is highly structured as several peaks in promoter activity were observed following DNA damaging UV irradiation. In our study we analyzed at the single cell level, the expression of the $\operatorname{rec} A$, lexA, and umuDC genes under physiological conditions using promoter fusions described previously [21]. Fluorescence microscopy revealed heterogeneity in the expression of all three genes. Based on fluorescence intensity, we found that the expression of $r e c A$ (Figure 3) and lexA was high in a small percentage of the cells, 3.1 and 1.5\%, respectively (Figure 2 and Table $3)$. In strains harboring the pore formers and DNase colicins transcriptional fusions to the $g f p$ gene, heterogeneity was exhibited as a small subpopulation of highly expressing cells within the large majority of non-expressing cells. On the other hand, among the $r e c A-g f p$ and lexA-gfp encoding populations, a small fraction exhibited high expression while the large majority exhibited basal level expression. The number of highly fluorescent cells harboring the recA-gfp fusion and their fluorescence intensity were higher compared with cells hosting lexA$g f p$. The HI of the recA SOS box is lower than of the lexA, predicting a higher affinity of LexA binding however, lexA harbors two SOS boxes. These results are in agreement with the higher basal level of the RecA protein compared to LexA, 7,200 versus 1,300 protein molecules per cell, respectively [28]. The higher levels of RecA protein could be explained by its roles in the SOS response, homologous recombination and its involvement in other repair mechanisms such as recombinational repair.

The SOS genes, $p o l B, \operatorname{din} B$ and $u m u D C$, encode specialized DNA polymerases II, IV and V respectively, which can bypass DNA lesions yet with reduced fidelity introducing mutations to newly synthesized DNA [29]. The operon encoding PolV is regulated by an SOS box that exhibits one of the highest predicted LexA binding affinities, with a $\mathrm{HI}$ of 2.77 [30]. It was shown that only upon full induction of the SOS response UmuD is synthesized and persists as a full length dimer [31]. 


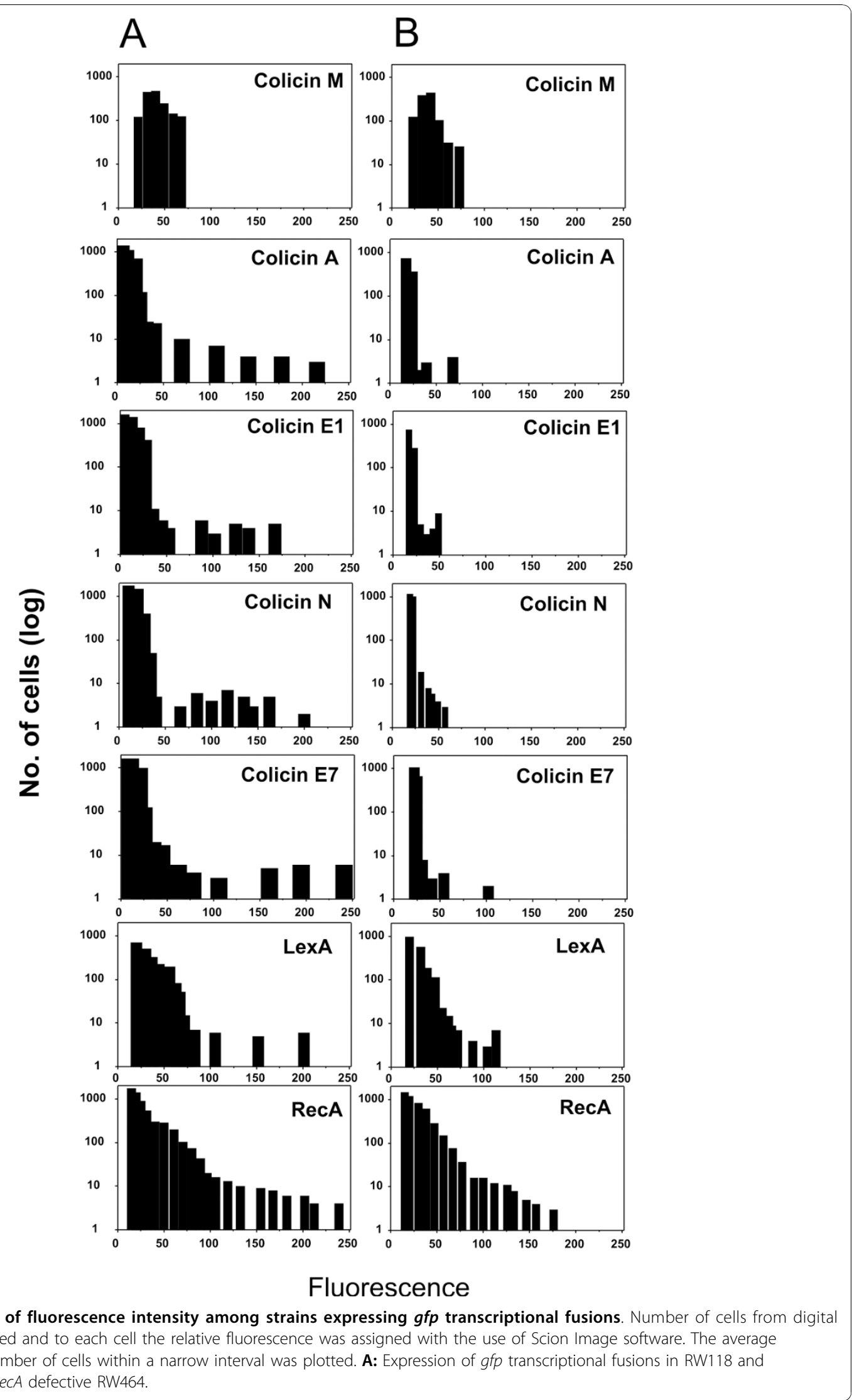


Table 3 Cells expressing SOS regulated genes in the wild type RW118

\begin{tabular}{|c|c|c|c|c|c|}
\hline$g f p$ transcriptional fusion & $\%$ of intensely fluorescent cells & Fluorescence threshold level* & Cell count & HI Distal & Proximal $^{\dagger}$ \\
\hline caa-gfp (pSC300) & 0.62 & 41 & 15555 & 11.52 & 9.73 \\
\hline cna-gfp (pSC301) & 0.51 & 41 & 9793 & 7.55 & 11.61 \\
\hline cela-gfp (pSC302) & 0.48 & 41 & 12197 & 7.48 & 11.06 \\
\hline ce7a-gfp (pSC303) & 1.55 & 41 & 9338 & 12.44 & 12.98 \\
\hline recA-gfp (pSC201) & 3.1 & 57 & 8366 & 4.31 & \\
\hline lexA-gfp (pSC200) & 1.48 & 57 & 5089 & 6.39 & 8.31 \\
\hline umuDC-gfp (pSC202) & 0.09 & 31 & 2083 & 2.77 & \\
\hline
\end{tabular}

*Fluorescence threshold level is defined as the point of clear transition from basal level (large majority of cells) to high fluorescence intensity.

${ }^{\dagger}$ Designated with regard to the ATG codon.

Accordingly, fluorescence emission from the $u m u D C-g f p$ fusion was observed in a very small fraction of the examined cells $(0.09 \%)$ and no detectable basal level of expression was observed among the large majority of the population. Our results show that in the absence of exogenous DNA damaging agents very low levels of $u m u D C$ promoter activity is detected. As translesion synthesis must be employed only when necessary, synthesis of the specialized polymerases is under physiological conditions controlled by complex regulation at the level of transcription and posttranslation.

\section{SOS regulated genes are expressed in a $\operatorname{rec} A$ defective strain}

Besides regulating DNA repair, induction of the SOS response has been recently shown to have a much broader role including, regulation of virulence factor synthesis in Staphylococcus aureus [31], type III secretion in enteropathogenic E. coli [32], subversion of innate defenses during urinary tract infection [33] and persistence to the fluoroquinolone antibiotic ciprofloxacin [34]. To examine to what extent expression of the investigated pore forming and DNase colicin activity genes as well as the recA, lexA and $u m u D C$ genes is dependent upon an SOS response under physiological conditions, expression was investigated in an isogenic $r e c A$ defective strain RW464 (Figure 2). Analysis at the

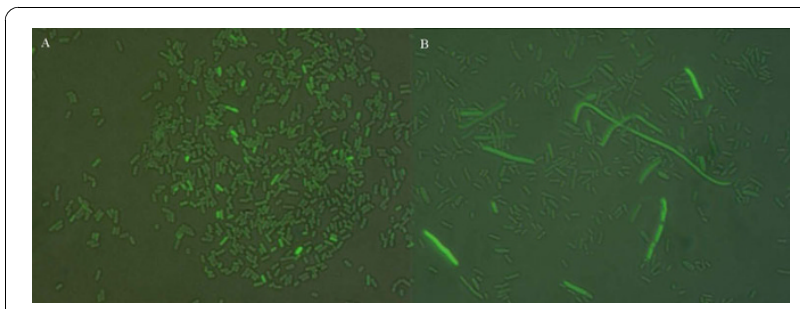

Figure 3 Merged images of the phase contrast and fluorescence images of $\mathbf{r e c} \boldsymbol{A}-\boldsymbol{g f p}$ expression. A: Expression of recA-gfp gene fusion in RW118 and $\mathbf{B}$ : Expression of recA-gfp fusion in the isogenic recA defective RW464 showing heterogeneity in expression of the recA gene. single cell level revealed reduction in the level of fluorescence and the number of intensely expressing cells harboring the $\operatorname{rec} A, \operatorname{lex} A, u m u D C, c a a$ as well as $c e 7 a-$ $g f p$ gene fusions and lower fluorescence of cells harboring cela and cna-gfp fusions. A greater reduction in the number of intensely expressing cells for colicin A (approximately ten fold) and colicin E7 (approximately three fold) was observed, while the percentage of cells expressing colicin $\mathrm{E} 1$ and $\mathrm{N}$ activity genes remained essentially unaltered (Figure 2, Table 4). The majority of the E. coli LexA regulon promoters are simple, being regulated only by a single transcriptional factor [35] however, some colicin encoding genes have additional regulation. Indeed, the CRP-cAMP complex was shown to stimulate expression of the colicin E1 activity gene ce1a by binding upstream from the ce1a SOS operator $[36,37]$. Interestingly, analysis of the colicin $\mathrm{N}$ promoter revealed a similar CRP binding site at the same location (Ghazaryan L., personal communication).

Both the $r e c A-g f p$ and $l e x A-g f p$ fusions were expressed in the recA defective strain RW464, albeit at a lower level compared to the wild type (Table 4, Figure 2, Figure 3), with a small fraction of the population exhibiting high fluorescence indicating that, stochastic factors could be involved. Filamentation due to delay in cell division is evident among the less robust $r e c A$ defective strain. However, expression of the investigated genes was not limited to filamented cells (Figure 3).

To resolve the effect of LexA regulation at the single cell level, expression of the investigated gene fusions was also studied in strain RW542 encoding a LexA protein defective in binding to LexA boxes. Fluorescence microscopy revealed that in the lexA defective strain all cells harboring the lexA-gfp or recA-gfp fusions, as well as the large majority $(98 \%)$ of the cells harboring $g f p$ fusions with the colicin activity genes were intensely fluorescent, indicating high level expression (data not shown).

\section{Simultaneous expression of the cka and SOS genes}

The advent of novel fluorescence markers enables analysis of simultaneous expression of two or more genes. To 
Table 4 Cells expressing SOS regulated genes in the recA defective strain RW464

\begin{tabular}{llll}
\hline gfp transcriptional fusion & \% of intensely fluorescent cells & Fluorescence threshold level* & Cell count \\
\hline caa-gfp (pSC300) & 0.075 & 26 & 9315 \\
\hline cna-gfp (pSC301) & 0.45 & 26 & 8938 \\
\hline cela-gfp (pSC302) & 0.36 & 26 & 7253 \\
\hline ce7a-gfp (pSC303) & 0.43 & 26 & 7050 \\
\hline recA-gfp (pSC201) & 1.69 & 52 & 5695 \\
\hline lexA-gfp (pSC200) & 0.53 & 52 & 2823 \\
\hline umuDC-gfp (pSC202) & 0.05 & 24 & 4004 \\
\hline
\end{tabular}

*Fluorescence threshold level is defined as the point of clear transition from basal level (large majority of cells) to high fluorescence intensity.

investigate in detail how the expression of colicin genes correlates with the expression of SOS genes, simultaneous expression of the $c k a$ and the $\operatorname{lex} A$ genes was followed at the single cell level in strain RW118 harboring two plasmids: pKCT10 with a cka-DsRed-Express 2 fusion and the pSC101 derivative vector harboring the lexA-gfp fusion. As is evident from Figure 4, the large majority of cells that more highly expressed the lexA gene also expressed the $c k a$ gene. Nonetheless, individual cells (approximately $0.1 \%$ ) highly expressing only the cka gene could be detected suggesting, that in a very small fraction of the population the colicin $\mathrm{K}$ activity gene is expressed in the absence of the SOS response most probably stochastically, due to perhaps intracellular fluctuations of the LexA protein. Filamentation while a hallmark of SOS induction due to binding of SulA to the FtsZ proteins is also evident in cells not expressing lexA-gfp (Figure 4). Multimers of the natural cka-gfp encoding plasmid could be responsible for filamentation in the absence of SOS induction [38].

In conclusion, to our knowledge this is the first study exploring a number of SOS regulated genes at the single cell level under physiological condition. Exposure of a population of bacterial cells to a DNA damaging agent induces the SOS response in all susceptible cells. However, under physiological conditions, genes regulated by the LexA protein also exhibit heterogenous expression. We show that genes with a very high affinity of LexA binding, characteristic of overlapping SOS boxes of colicin operators, or very low HI such as $u m u D C$, are expressed in only a small fraction of the population and exhibit no detectable basal level expression. In contrast, genes of the SOS regulon with a somewhat lower predicted affinity of LexA binding, such as $\operatorname{lex} A$ and $\operatorname{rec} A$, while also fully expressed in a small subpopulation, exhibit basal level expression. Intense fluorescence of cells harboring the investigated gene fusions was observed in a lexA defective strain indicating that the LexA protein effectively represses promoter activity in the large majority of cells. Some of the examined cells could be experiencing disruption of replication forks during replication and thus induction of the SOS response. However, expression of all of the investigated genes was observed in a $\operatorname{rec} A$ mutant, which cannot

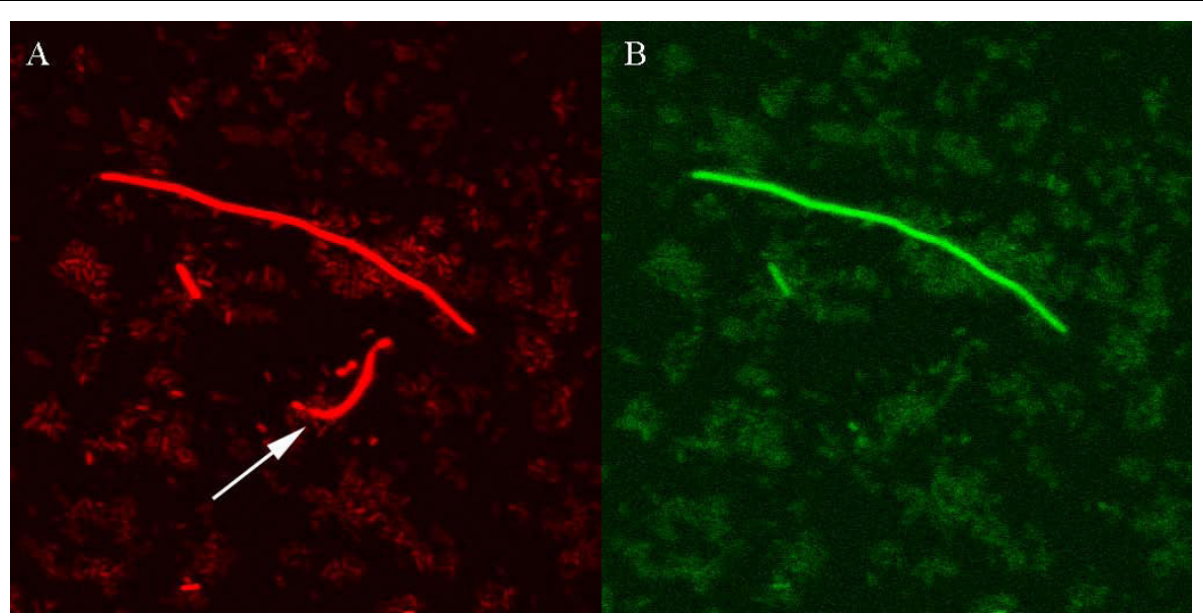

Figure 4 Fluorescence images showing simultaneous expression of the cka-DsRed-Express 2 and lexA-gfp transcriptional fusions. A: Expression of cka-DsRed-Express2 gene fusion. B: Expression of lexA-gfp gene fusion in RW118. The arrow indicates a cell with high level expression of $c k a$, but not lexA, showing that colicin activity gene expression can occur in the absence of the SOS response. 
instigate an SOS response indicating that, expression of LexA regulated genes also occurs stochastically.

Expression of colicin genes under physiological conditions by a small subpopulation may promote strain and genetic diversity and due to lysis of producing cells could provide resources to facilitate growth of nonexpressing cells. On the other hand, a subpopulation of cells with higher levels of the RecA protein may be more proficient in recombination, e.g. for the stable incorporation of horizontally acquired DNA or a rapid response to DNA damage. We can speculate that heterogeneity of expression of lexA in $E$. coli affects a number of phenomenon significant for antibiotic tolerance/ resistance (persisters), horizontal gene transfer (induction of prophage) and virulence among pathogenic E. coli strains. The same might apply to other gram negative (e.g. Shigella, Salmonella, Pseudomonas aeruginosa) and gram positive (e.g. S. aureus, B. subtilis) bacterial species that possess a system similar to the $E$. coli SOS system.

\section{Conclusion}

LexA regulated SOS genes exhibit heterogeneity as they are highly expressed in only a small subpopulation of cells. Unlike $\operatorname{rec} A$ and $\operatorname{lex} A$, the colicin activity genes and $u m u D C$ exhibit no basal level expression. Heterogenous expression is established primarily by stochastic factors as well as the binding affinity of LexA to SOS boxes.

\footnotetext{
Acknowledgements

We thank Ben Glick for generously providing pDsRed-Express2-N1 as well as Uri Alon for strains carrying the lexA-gfp, recA-gfp and umuDC-gfp fusions. This work was funded by grant P1-0198 from the Slovenian Research Agency (ARRS) and the FP6 Sixth EU framework programme for Research and Technological Development: Transnational Access, Dryland Research Specific Support Action (SSA), Jacob Blaustein Institutes of Desert Research, Ben Gurion University of the Negev.

Simona Kamenšek is a recipient of a Ph.D grant from ARRS
}

\section{Author details}

'Dept. of Biology, Biotechnical Faculty, University of Ljubljana, Večna pot 111, Slovenia. ${ }^{2}$ Zuckerberg Institute for Water Research, J. Blaustein Institutes for Desert Research, Ben-Gurion University, Israel.

\section{Authors' contributions}

SK performed all experiments. ZP contributed to analysis of the results. OG and $D Z ̌ B$ participated in the design of the experiments and $S K, O G$ and $D Z ̌ B$ in preparation of the manuscript. All authors read and approved the final manuscript.

Received: 16 July 2010 Accepted: 11 November 2010 Published: 11 November 2010

\section{References}

1. Dubnau D, Losick R: Bistability in bacteria. Mol Microbiol 2006, 61:564-572

2. Veening JW, Smits WK, Kuipers OP: Bistability, epigenetics, and bethedging in bacteria. Annu Rev Microbiol 2008, 62:193-210.

3. Mrak P, Podlesek Z, van Putten JPM, Žgur-Bertok D: Heterogeneity in expression of the Escherichia coli colicin $\mathrm{K}$ activity gene cka is controlled by the SOS system and stochastic factors. Mol Gen Genet 2007, 277:391-401.

4. Keren I, Kaldalu N, Spoering A, Wang Y, Lewis K: Persister cells and tolerance to antimicrobials. FEMS Microbiol Lett 2004, 230:13-18.

5. Friedberg EC, Walker GC, Siede W, Wood RD, Schultz RS, Ellenberger T: DNA repair and mutagenesis. ASM press, Washington, $D_{i}$, 22006-957.

6. Radman M: Phenomenology of an inducible mutagenic DNA repair pathway in Escherichia coli: SOS repair hypothesis. In Molecular and environmental aspects of mutagenesis. Edited by: Prakash L, Sherman F, Miller C, Lawrence C, Tabor HW. Springfield, Illinois: Charles C. Thomas Publisher; 1974:128-142.

7. Erill I, Escribano M, Campoy S, Barbé J: In silico analysis reveals substantial variability in the gene contents of the gamma proteobacteria LexAregulon. Bioinformatics 2003, 19:2225-2236.

8. Cascales E, Buchanan SK, Duché D, Kleanthous C, Lloubès R, Postle K, Riley M, Slatin S, Cavard D: Colicin biology. Microbiol Mol Biol Rev 2007, 71:158-229.

9. Kirkup BC, Riley MA: Antibiotic mediated antagonism leads to a bacterial game of rock-paper-scissors in vivo. Nature 2004, 428:412-414.

10. Walker D, Rolfe M, Thompson A, Moore GR, James R, Hinton CD, Kleanthous C: Transcriptional profiling of colicin-induced cell death of Escherichia coli MG1655 identifies potential mechanisms by which bacteriocins promote bacterial diversity. J Bacteriol 2004, 186:866-869.

11. Braun V, Schaller K, Wabl MR: Isolation, characterization and action of colicin M. Antimicrob Agents Chemother 1974, 5:520-533.

12. Harkness RE, Braun V: Inhibition of lipopolysaccharide O-antigen synthesis by colicin-M. J Biol Chem 1989, 264:14716-14722.

13. Harkness RE, Braun V: Colicin-M inhibits peptidoglycan biosynthesis by interfering with lipid carrier recycling. J Biol Chem 1989, 264:6177-6182.

14. Lu FM, Chak KF: Two overlapping SOS boxes in ColE operons are responsible for the viability of cells harboring the Col plasmid. Mol Gen Genet 1996, 251:407-411.

15. Harkness RE, Ölschläger T: The biology of colicin-M. FEMS Microbiol Rev 1991, 8:27-41.

16. Ölschläger T, Schramm E, Braun V: Cloning and expression of the activity and immunity genes of colicin B and colicin M on ColBM plasmids. Mol Gen Genet 1984, 196:482-487.

17. Sasarman S, Massie B, Zollinger M, Gagnetellier H, Shareck F, Garzon S, Morisset $R$ : Naturally occuring RcolBM plasmids belonging to the Incflll incompatibility group. J Gen Microbiol 1980, 119:475-483.

18. Gillor O, Vriezen JAC, Riley MA: The role of SOS boxes in enteric bacteriocin regulation. Microbiology 2008, 154:1783-1792.

19. Mulec J, Podlesek Z, Mrak P, Kopitar A, Ihan A, Žgur-Bertok D: A cka-gfp transcriptional fusion reveals that the colicin $\mathrm{K}$ activity gene is induced in only 3 percent of the population. J Bacteriol 2003, 185:654-659.

20. Sambrook J, Russell D: Molecular cloning: A laboratory manual. Cold Spring Harbor Laboratory, Cold Spring Harbor, N.Y; 2001.

21. Ronen M, Rosenberg R, Shraiman BI, Alon U: Assigning numbers to the arrows: Parameterizing a gene regulation network by using accurate expression kinetics. Proc Natl Acad Sci USA 2002, 16:10555-10560.

22. Strack RL, Strongin DE, Bhattacharyya D, Tao W, Berman A, Broxmeyer HE, Keenan RJ, Glick BS: A nontoxic DsRed variant for whole-cell labeling. Nature methods 2008, 5:955.

23. Lewis KL, Harlow GR, Gregg-Jolly LA, Mount DW: Identification of high affinity binding sites which define new DNA damage-inducible genes in Escherichia coli. J Mol Biol 1994, 241:507-523.

24. Christenson JK, Gordon DM: Evolution of colicin BM plasmids: the loss of colicin B activity gene. Microbiology 2009, 155:1645-55.

25. McCool JD, Long E, Petrosino JF, Sandler HA, Rosenberg SM, Sandler SJ: Measurement of SOS expression in individual Escherichia coli K-12 cells using fluorescence microscopy. Mol Microbiol 2004, 53:1343-1357.

26. Husiman O, Dari R, Gottesman S: Cell-division control in Escherichia coli: specific induction of the SOS function SfiA protein is sufficient to block septation. Proc Natl Acad Sci USA 1984, 81:4490-4494.

27. Friedman N, Vardi S, Ronen M, Alon U, Stavans J: Precise temporal modulation in the response of the SOS DNA repair network in individual bacteria. PLoS biol 2005, 3:1261-1268.

28. Sassanfar M, Roberts JW: Nature of the SOS-inducing signal in Escherichia coli: the involvement of DNA replication. J Mol Biol 1990, 212:79-96.

29. Napolitano R, Janel-Blintz R, Wagner J, Fuchs RP: All three SOS-inducible DNA polymerases (PollI, PollV and PolV) are involved in induced mutagenesis. Nat Rev Mol Cell Biol 2000, 8:6259-6265. 
30. Fernandez de Henestrosa AR, Ogi T, Aoyagi S, Chafin D, Hayes JJ, Ohmori H, Woodgate R: Identification of additional genes belonging to the LexA regulon in Escherichia coli. Mol Microbiol 2000, 35:1560-1572.

31. Bisognano C, Kelley WL, Estoppey T, Francois P, Schrenzel J, Li D, Lew DP, Hooper DC, Cheng AL, Vaudaux P: A RecA-LexA dependent pathway mediates ciprofloxacin-induced fibronection binding in Staphylococcus aureus. J Biol Chem 2004, 279:9064-9071.

32. Mellies JL, Haack KR, Galligan DC: SOS regulation of the type III secretion system of enteropathogenic Escherichia coli. J Bacteriol 2007, 189:2863-2872.

33. Justice SS, Hung C, Theriot JA, Fletcher DA, Anderson GG, Footer MJ, Hultgren SJ: Differentiation and developmental pathways of uropathogenic Escherichia coli in urinary tract pathogenesis. Proc Natl Acad Sci USA 2004, 101:1333-1338.

34. Dörr T, Lewis K, Vulić M: SOS response induces persistence to fluoroquinolones in Escherichia coli. PLoS Genetics 2009, 5:1-9.

35. Keseler IM, Bonavides-Martinez C, Collado-Vides J, Gama-Castro S, Gunsalus RP, Johnson DA, Krummenacker M, Nolan LM, Paley S, Paulsen IT, et al: EcoCyc: a comprehensive view of Escherichia coli biology. Nucleic Acids Res 2009, 37:D464-470.

36. Salles B, Weisemann JM, Weinstock GM: Temporal control of colicin E1 induction. J Bacteriol 1987, 169:5028-5034.

37. Salles B, Weinstock GM: Interaction of the CRP-cAMP complex with the cea regulatory region. Mol Gen Genet 1989, 215:537-542.

38. Chant EL, Summers DK: Indole signaling contributes to the stable maintenance of Escherichia coli multicopy plasmids. Mol Microbiol 2007, 63:35-43.

doi:10.1186/1471-2180-10-283

Cite this article as: Kamenšek et al:: Genes regulated by the Escherichia coli SOS repressor LexA exhibit heterogenous expression. BMC Microbiology 2010 10:283.

\section{Submit your next manuscript to BioMed Central and take full advantage of:}

- Convenient online submission

- Thorough peer review

- No space constraints or color figure charges

- Immediate publication on acceptance

- Inclusion in PubMed, CAS, Scopus and Google Scholar

- Research which is freely available for redistribution

Submit your manuscript at www.biomedcentral.com/submit 